\title{
44
}

\section{Scientific Challenges to Free Will}

\author{
EDDY NAHMIAS
}

Scientists have recently claimed that their discoveries challenge free will. For instance, psychologist Jonathan Bargh concludes that "The phenomenological feeling of free will is very real [...] but this strong feeling is an illusion" (2008: 148-149). Neuroscientist John-Dylan Haynes claims that his functional magnetic resonance imaging (fMRI) research shows that

[t]here's not very much space for operation of free will. The outcome of a decision is shaped very strongly by brain activity much earlier than the point in time when you feel to be making a decision. (Youngsteadt 2008)

And neuroscientists Joshua Greene and Jonathan Cohen conclude: "The net effect of this influx of scientific information will be a rejection of free will as it is ordinarily conceived with important ramifications for the law" (2004: 1776). Indeed, what scientists say about free will could have a significant impact not only on our legal practices, but on our conception of ourselves and of others as morally responsible agents. This impact is likely to be exacerbated by the way in which the research is presented by the science media. For instance, ScienceNews reports: " 'Free will' is not the defining feature of humanness, modern neuroscience implies, but is rather an illusion that endures only because biochemical complexity conceals the mechanisms of decision making" (12/6/08). And Jeffrey Rosen asks: "And since all behavior is caused by our brains, wouldn't this mean all behavior could potentially be excused?" (New York Times 3/11/07).

It is therefore important to consider carefully what discoveries these scientists take to be challenging free will and whether these claims are justified. In the present essay I take on this task, first by distinguishing among various ways the research might pose challenges to free will, then by considering whether it actually does.

Philosophical debates about free will focus largely on one question: is free will compatible with determinism? So the most straightforward scientific challenge to free will would seem to be the discovery of determinism. Indeed, scientists often explicitly argue that: 


\section{EDDY NAHMIAS}

[D1] Free will requires that determinism is false.

[D2] Science is showing that determinism is true.

[D3] So, science is showing that we do not have free will.

For instance Bargh writes: "The psychological issue of whether free will exists thus boils down to whether undetermined choices of action exist" (2008: 130), and he and Ferguson take their research to "present the case for the determinism of higher mental processes" (2000: 926). Lawrence Tancredi writes: "Free will, long considered a hallmark of what makes us human, seems to be losing ground to claims of biological determinism" (2007: 305).

One problem with this argument is that the scientists simply assume that premise [D1] is true, ignoring the substantial philosophical literature supporting compatibilism, the view that free will does not require the falsity of determinism (see McKenna 2004). Perhaps these scientists take incompatibilism to be commonsensical, but this assumption is controversial and may be based on confusing determinism with different threats to free will (Nahmias et al. 2006, 2007b). More importantly, science is not showing determinism to be true. Determinism, as understood in the incompatibilists' arguments for [D1] (see for instance van Inwagen 1983), is the thesis that a complete description of a system at one time, conjoined with a complete description of the laws which govern that system, entails a complete description of that system at any future time. In a deterministic system, given identical circumstances, the same causal antecedent will always have the exact same effects. But the dominant interpretation in quantum physics suggests that determinism, so defined, is false. While some philosophers have looked to quantum indeterminism in the hope that it might allow for free will (Kane 1996), most conclude that such indeterminism would not provide us with any relevant type of control which we could not have without it. This should make us wonder why philosophers focus so much attention on determinism and whether they are neglecting scientific discoveries seemingly more relevant to human free will - namely discoveries about human psychology rather than discoveries in microphysics.

In fact the scientists who are claiming that free will is an illusion are not physicists. They are neuroscientists and psychologists. While, in practice, these scientists may aspire to offer deterministic explanations and laws for the systems they study, these sciences are not in a position to establish determinism. Most of their discoveries involve statistical correlations that are compatible with indeterminism. Moreover, it is implausible to think that indeterministic interactions at the microphysical level never have an effect on the way things happen at, say, the neurobiological level. And "near-enough determinism' is simply not sufficient to make incompatibilist arguments go through (i.e., to justify premise D2).

It turns out that these skeptical scientists are not really working with a philosophical conception of determinism. Rather they tend to use 'determinism' to mean something else, namely mechanism. Mechanism is the view that mental phenomena can be fully explained in terms of their component neurobiological parts and in terms of the organization of, and interactions between, these parts (see Craver 2007). Consider how neuroscientist Benjamin Libet defines 'determinism' in terms of mechanism, explicitly setting aside quantum indeterminism: 
But we have not answered the question of whether our consciously willed acts are fully determined by natural laws that govern the activities of nerve cells in the brain, or whether conscious decisions can proceed to some degree independently of natural determinism [...] Quantum mechanics forces us to deal with probabilities rather than with certainties of events [...] [but] they might nevertheless be in accord with natural laws and therefore determined. (Libet 1999: 55)

Bargh and Ferguson make a similar move:

We consider the discovery and delineation of the causal mechanisms that underlie these [conscious] processes and the quest for supplying mechanisms [...] as the critical and defining criteria of the deterministic stance. (Bargh and Ferguson 2000: 926)

This sort of mechanism could clearly be true even if determinism is false (for example if any of the component parts in a mechanistic system interact in indeterministic ways). Conversely, determinism could be true even in a non-mechanistic system (for example if both physical laws and psychological laws are deterministic, but psychological processes cannot be fully explained in terms of physical processes). Hence it is misleading to present determinism as a threat to free will by trading on threats posed by mechanism or vice versa.

We need a different argument to represent the challenge to free will that psychologists and neuroscientists have in mind:

[M1] Free will requires that mechanism is false.

[M2] Science is showing that mechanism is true.

[M3] So, science is showing that we do not have free will.

As with determinism, it is not clear that these sciences are discovering that mechanism is true [M2] rather than assuming it as a useful heuristic. One might, however, argue that these sciences provide inductive support for mechanism to the extent that they offer evidence that human decision-making and behavior can be explained and predicted in terms of underlying mechanisms. But in this case none of the specific results discussed as challenges to free will (for instance, those considered below) is particularly relevant to this argument.

Premise [M1] is more controversial. It may be motivated by the assumption that free will, by definition, involves non-natural powers. Consider the way neuroscientist Read Montague puts it:

Free will is the idea that we make choices and have thoughts independent of anything remotely resembling a physical process. Free will is the close cousin to the idea of the soul - the concept that 'you,' your thoughts and feelings, derive from an entity that is separate and distinct from the physical mechanisms that make up your body [...] Consequently, the idea of free will is not even in principle within reach of scientific description. (Montague 2008: 584)

Psychologist Daniel Wegner assumes that we are dualists about free will: "Seeing one's own causal influence as supernatural is part of being human" (2008: 228). And Greene 


\section{EDDY NAHMIAS}

and Cohen write: "intuitive free will [...] requires the rejection of determinism and an implicit commitment to some kind of magical mental causation" (2004: 178). But it is entirely unclear whether most ordinary people assume that free will requires nonnatural powers, and even less clear that they associate it primarily with such powers rather than with the sorts of powers compatibilists emphasize, such as self-control and rational deliberation. Philosophers certainly aim to analyze free will in ways that are consistent with our best scientific picture of decision-making; no serious contemporary accounts of free will appeal to substance dualism.

In order to examine whether specific scientific evidence about human decisionmaking challenges free will, we should begin with the assumption that a naturalistic account of free will is possible. On that assumption, some discoveries may help to explain free will rather than explaining it away. Nonetheless, recent evidence from psychology and neuroscience could challenge free will on the basis of an argument like this:

[E1] Free will requires that one's actions properly derive from one's conscious reasoning, decisions, and intentions.

[E2] Science is showing that our actions do not properly derive from our conscious reasoning, decisions, and intentions.

[E3] So, science is showing that we do not have free will.

Free will, as understood in [E1], is consistent with determinism. Whether it is consistent with mechanism or not is an issue which leads to metaphysical debates about mental causation and 'philosophical epiphenomenalism.' Some philosophers think that conscious mental states cannot play a causal role in action if they supervene on neural states - that is, if changes in mental states depend on changes in neural states (Kim 1998). But the scientific evidence is not relevant to these debates, since the debates begin with the assumption that our mental states supervene on our neural states. For the scientific evidence to be relevant to this argument, we need to consider whether it adds support to [E2] on the naturalistic assumption that all mental processes supervene on 'neural correlates.' This question then turns on whether there is evidence for a thesis which I call 'modular epiphenomenalism' (Nahmias 2002). This is the thesis that the neural correlates of our conscious experience of deciding or intending an action (the ' $\mathrm{C}$ module') are not causally responsible for producing that action; instead, distinct, nonconscious processes or modules (the 'NC modules') cause the action, while NC modules also cause the activity in the C modules (see Figure 44.1). Hence 'conscious will' is an illusion (Wegner 2002) in that the processes underlying our conscious choices and intentions do not in fact cause our actions - they are epiphenomenal.

Modular epiphenomenalism finally offers an empirical thesis that appears to challenge free will and can be informed by recent scientific evidence, rather than relying primarily on controversial philosophical claims. So now we are in a position to examine some of this research and then to consider whether it is properly interpreted as a challenge to free will.

Libet's much discussed work represented the first such challenge. Libet (1985) demonstrated that voluntary muscle movements (flexing one's wrist) are preceded by "readiness potentials" (RPs), brain waves in the supplemental motor area (SMA) which occur about half a second $(500 \mathrm{~ms})$ before the movement. Libet also had subjects report 


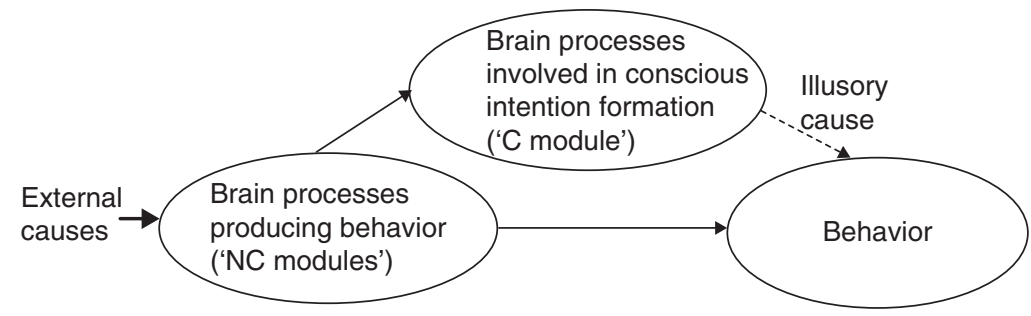

Figure 44.1 Modular epiphenomenalism (compare Wegner 2002: 68)

when they became aware of the "intention, desire, or urge" to move, and this measure suggested that awareness occurred only $150 \mathrm{~ms}$ before the movement $350 \mathrm{~ms}$ after the RP. Libet concluded that voluntary actions "begin in the brain unconsciously, well before the person consciously knows he wants to act" (1999: 51). Libet interpreted this result as showing that our conscious intention to move is not the cause of our movement but, like the movement itself, an effect of earlier (nonconscious) brain activity. Libet seems to assume that conscious intentions are nonphysical; but, if we reject this dualist assumption, his data look like evidence for modular epiphenomenalism: the RP in the SMA is a non-conscious process that causes the movement, while the neural correlates of the conscious experience of intending to move are shown to be epiphenomenal because they occur too late to initiate the movement. If this model of agency applied to all actions, it would appear to reduce the role of consciousness to one of merely observing unconsciously formed decisions instead of making them.

Libet's paradigm has recently been extended in an fMRI study. Soon et al. (2008) asked subjects to press a button either with their left or with their right index finger "when they became aware of the urge to do so" and to pay attention to when "their motor decision was consciously made." Consistent with Libet's results, subjects generally reported that they were aware of their "decision" less than half a second before pressing the button. But analyses of the fMRI data showed specific activity in the frontopolar cortex that predicted which button subjects would press 7-10 seconds before the movement! And activity in SMA predicted when subjects would press the button about 5 seconds before the movement. It should be noted that, while statistically significant, these 'predictions' (actually post-hoc correlations) could be made with only 60 percent accuracy (that is, 10 percent above chance). The authors conclude that

two specific regions in the frontal and parietal cortex of the human brain had considerable information that predicted the outcome of a motor decision the subject had not yet consciously made. (Soon et al. 2008: 545)

They take these findings to bolster Libet's case that the "subjective experience of freedom is no more than an illusion and that our actions are initiated by unconscious mental processes long before we become aware of our intention to act" (ibid., p. 543). Assuming that further studies could drive the predictive accuracy much higher, 


\section{EDDY NAHMIAS}

modular epiphenomenalism and premise [E2] look plausible: non-conscious neural processes, not the neural correlates of conscious decisions, cause actions that we experience as freely chosen.

A third research paradigm suggesting modular epiphenomenalism appears in the work of psychologists such as Wegner and Bargh. As we have seen, these authors suggest that simply discovering that there are underlying brain processes for decisions and actions is a threat to free will. For instance, Wegner suggests that conscious will is an illusion because "the real causal sequence underlying human behavior involves a massively complicated set of mechanisms" (2002: 27). But if we put aside such assumptions and focus on the actual evidence these psychologists discuss, we can consider whether this evidence lends support to modular epiphenomenalism. Though Wegner and Bargh discuss neuroscientific research such as Libet's, their focus is on psychological evidence - evidence, for instance, of people performing voluntarylooking actions without conscious awareness of performing those actions or without conscious decisions to perform those actions. This evidence is taken to suggest that, because non-conscious processes can produce actions normally accompanied by consciousness, consciousness is unnecessary and hence causally irrelevant. Bargh and Ferguson conclude:

the same higher mental processes that have traditionally served as quintessential examples of choice and free will - such as goal pursuit, judgment, and interpersonal behavior - have been shown recently to occur in the absence of conscious choice or guidance. (2000: 926)

Wegner focuses on cases where people lack an experience of consciously willing a bodily movement that they in fact brought about (as in automatisms, or in hypnosis), and also on cases where people experience some sense of agency in relation to a bodily movement or an event which they do not in fact cause (see for example his I-Spy study, 2002: 74). Wegner takes these seemingly exceptional cases to represent the rule that our conscious intentions never cause our actions:

Rather than conscious will being the rule and automatism the exception, the opposite may be true: Automatism is the rule, and the illusion of conscious will is the exception. (Ibid., p. 143)

And he suggests modular epiphenomenalism:

The brain, in turn, shows evidence that the motor structures underlying action [NC modules] are distinct from the structures that allow the experience of will [C module]. The experience of will may be manufactured by the interconnected operation of multiple brain systems, and these do not seem to be the same as the systems that yield action. (Ibid., p. 49)

Wegner's explanation for our illusory experiences of conscious will is that we have relevant conscious thoughts just prior to the action, while being unaware of any competing causes of the action. But these thoughts are themselves caused by prior nonconscious brain activity, such that conscious intention "might just be a loose end - one 
of those things, like the action, that is caused by prior brain and mental events" (ibid., p. 55; see Figure 44.1).

Now that we have seen the sort of evidence from neuroscience and psychology that has been taken to challenge free will, I will first argue that such evidence does not clearly demonstrate modular epiphenomenalism - that is, premise [E2] - and then argue that, even to the extent that it could, this would not pose much of a threat to free will, once we parse premise [E1] more carefully (for more detailed responses to Wegner and Libet, see Nahmias 2002 and Mele 2009).

Wegner and Bargh face a dilemma: they must either take the evidence they describe to suggest that the causal role of consciousness is limited in scope (and further work will delimit this scope), or use it as inductive evidence for the general rule that conscious processes are never causal. Bargh and Ferguson admit that the evidence they discuss shows only that conscious processes play a less significant role that we tend to assume: "This research has found much of an individual's complex psychological and behavioral functioning to occur without conscious choice or guidance - that is, automatically" (2000: 941). Plugging this claim into the argument for epiphenomenalism would only generate the conclusion that we have less free will than we tend to think rather than none at all. Though I think the scope of this threat is more limited than the authors suppose (see below), not even Bargh's claim of "mainly unconscious instead of conscious causation of action" (2008: 148) entails the skeptical conclusion that free will is an illusion.

Wegner tends to take the other horn of the dilemma and to draw more general conclusions about epiphenomenalism. However, to demonstrate that the neural correlates of conscious intentions are causally cut off from the neural processes which produce actions would require data from the neurosciences, and here Wegner has little to offer beyond Libet's work. The unusual cases from the psychological literature (voluntary-looking movements without the agent's experiencing control, and small increases in reported experiences of control over events which the agent did not actually cause) demonstrate only that the experience of will is not always veridical, not that it is never veridical. Without the neuro-anatomical data to demonstrate that the relevant brain processes are causally unconnected, the best interpretation for these "illusions of will" should be guided by an analogy with visual illusions, which certainly do not demonstrate that our visual experiences are systematically mistaken. Indeed, as with visual illusions, explanations for illusions of will may be offered in terms of a generally reliable system, which sometimes produces inaccurate output because of some unusual feature of the situation (all the cases discussed by Wegner are unusual in important ways). The fact that we sometimes perform complex behaviors without conscious intentions (for example, under hypnosis or with subliminal priming) does not show that, on the many occasions when we do perform complex behaviors with conscious intentions, the conscious mental processes are causally irrelevant.

But doesn't the neuroscientific evidence presented by Libet and by Soon and colleagues give us reason to think that the neural correlates of conscious intentions and decisions are not causes of our actions? Not really. Their data are entirely consistent with other interpretations. For instance, RPs and the even earlier activity in the frontopolar cortex may correlate with non-conscious urges to move soon (or to push the 


\section{EDDY NAHMIAS}

left or right button), rather than with specific intentions or decisions. In the experiments, this non-conscious activity almost always leads to a consciously experienced intention and corresponding action, but in some cases the urge may be "vetoed," perhaps by the subjects' conscious intention not to act on that urge (Mele 2009). The data is simply not sufficient to show that the non-conscious neural activity deterministically causes a particular action (such that, given that activity, the action must happen). Libet did not even analyze data on brain activity in cases where subjects felt the urge to flex but did not flex. And recall that Soon's group could only show that the early brain activity predicted the choices at 10 percent above chance, which leaves open the possibility that, on some trials, later conscious thoughts, whose neural correlates could not be captured in the analyses, influenced which button was pressed and when. This interpretation, if true, allows that the neural correlates of conscious intentions can causally influence when, whether, and how a person acts, contra premise [E2].

Another possibility is that the early non-conscious brain activity just is part of the correlate of the conscious intention, or part of the necessary build-up to such intentions or decisions. After all, if we assume that conscious processes correlate with neural processes, we should expect that conscious experiences do not arise out of nowhere and in no time (Dennett 1991). Rather, they will be produced by earlier complexes of events, including external stimuli and neural activity, some of which may have been caused by even earlier conscious processes. For instance, in these experiments subjects consciously processed and accepted the experimenters' instructions, which in the trials conducted by Soon and his colleagues were "to press either the left or right button with the index finger of the corresponding hand immediately when they became aware of the urge to do so" (2008: 15) and "to avoid any form of preplanning for choice of movement or time of execution" (ibid., p. 17; Libet's instructions were similar). If the subjects followed these instructions, they probably formed a distal intention (or plan) to allow urges to press a button arise within them, and to pay attention to when the urge arises. In the circumstances, it is likely, on the one hand, that this (conscious) distal intention or plan causally influenced the spontaneous generation of non-conscious urges to act and, on the other hand, that subjects may not be reporting awareness of a consciously formed intention to act now, but rather awareness of an urge to act. (This interpretation becomes more plausible when we consider that subjects in these experiments must repeat tedious button-presses many dozens of times, so that the action may become more habitual and automatic.)

Of course, these alternative interpretations might be mistaken; evidence might surface to show that, whenever we consciously intend an action just before we act, our being conscious (and the underlying neural processes) simply occurs too late to influence the action causally (and the neural correlates of this proximal intention are not 'hooked up' to the action-production system). However, even if this turned out to be true - and again, the evidence has not yet shown it to be true - I do not think it would represent a significant threat to free will. Consider your own experiences of most voluntary actions. If they are like mine, they rarely involve specific conscious intentions to move in particular ways just prior to moving. Rather, they are preceded by more distal intentions and general plans to carry out various actions, which are followed by conscious monitoring of what we are doing to make sure that the actions correspond to these previously formed intentions and plans. 
For instance, in these experiments, even if there are proximal conscious intentions to move and they occur too late to affect the action, it would not follow that all relevant conscious mental states were epiphenomenal, since the subjects' consciously agreeing to move when the urge strikes them surely plays a role in their later actions. Similarly, when we drive or play sports or prepare meals, we do not generally form conscious intentions to perform each of the component actions involved in these activities. When we lecture to students or converse with friends, we tend not to think about exactly what we are going to say right before we say it. Rather we may consciously consider what sorts of things we want to say, and then we 'let ourselves go,' though we consciously monitor what's happening and consider how to proceed, for instance, in response to what our students or friends say. Whereas I take these actions that accord with earlier conscious deliberations to be paradigmatic examples of freely willed actions, Bargh suggests just the opposite when he says:

Our ability to take a vague thought and have it come out of our mouths in a complete coherent sentence, the production of which happens unconsciously, is ... not something we need consciousness or free will for. (2008: 145)

On many theories of free will, what is essential is not that conscious intentions formed just prior to action cause one's actions, but that conscious deliberations can have a proper downstream effect on the way one acts in the relevant situations, such that we act in accord with reasons that we have consciously considered and accepted at some point. There is simply no evidence (yet) to show that conscious deliberation, reasoning, and planning have no such effects on what we do, or that our conscious monitoring of our behavior is not critically involved in the way we carry out and adjust our actions. Indeed there is evidence to the contrary - situations which indicate the crucial roles that conscious intention formation, rational thinking, and 'willpower' play in some of our actions (Gollwitzer 1999; Baumeister 2008).

Of course, empirical evidence from neuroscience and psychology could show that these 'downstream' roles of conscious mental processes are less significant than we tend to think. Indeed some research on moral reasoning seems to suggest that, when people make moral judgments, they often act on immediate gut reactions and then their conscious deliberations merely come up with post hoc rationalizations of these reactions (Haidt 2001; Greene 2007). Furthermore, research in social psychology suggests that we are often influenced by situational factors of which we are unaware and whose influence we would not accept, were we aware of them. For instance, whether people help someone in need depends less on whether the person needs help or on whether one considers oneself a helpful person than on factors such as the number of bystanders, the ambient noise, or whether one is in a hurry (Ross and Nisbett 1991; Doris 2002). This view suggests one more scientific challenge to free will (Nahmias 2007a):

[R1] Free will requires that one's actions properly derive from decisions or intentions that one has at some point consciously considered, or at least that one would accept, as one's reasons for acting.

[R2] Science is showing that our actions do not properly derive from decisions or intentions that we have consciously considered or would accept as our 
reasons for acting. Rather, our actions are produced by other factors, and we rationalize them after the fact.

[R3] So, science is showing that we do not have free will.

I find [R1] plausible, and I think that most philosophical theories of free will accept something like it. Though the existing neuroscientific research does not say much about premise [R2], research in psychology offers evidence of numerous cases where we don't know why we do what we do and make up reasons for why we did what we did. This research has not, however, established that conscious reasoning is always post hoc and inefficacious, and I suspect it will not establish such a sweeping conclusion. On the other hand, it may show that we have less free will than we tend to think we have - that our capacities for conscious reasoning and control are less efficacious than we generally assume. Hence scientific research may challenge the degree to which we have free will - and perhaps, in turn, the degree to which we are morally responsible for our actions.

We now have a better sense of various ways to interpret recent scientific challenges to free will. If such challenges begin with the assumption that free will is incompatible with determinism or with mechanism, then they must rely on controversial philosophical arguments, and it is unclear how specific research in psychology and neuroscience will advance these arguments. Such research, however, could show that conscious processes (and their neural correlates) are not the proximal cause of action. Such 'modular epiphenomenalism,' however, has not yet been established by the relevant research in neuroscience and psychology, and the challenge it poses to free will might be minimal as long as conscious deliberation and planning have the proper "downstream' influence on actions. Indeed, the scientific discoveries which seem to pose the most significant challenge to free will are those which suggest that our conscious deliberations and reasoning do not contribute to our later actions, but only to our post hoc rationalizations of such actions. As I am someone who thinks that free will, properly understood, is compatible with determinism, with mechanism, and even with modular epiphenomenalism, it is this evidence for systematic rationalization that I find most threatening. Luckily, I think that future research will show this challenge to be limited in scope. But I may just be rationalizing.

When science claims to have discovered that humans have no free will - and headlines read "Case closed for free will?" (Youngsteadt 2008) - people will interpret such claims in terms of their own conceptions of free will. The danger is that most people do not take free will to involve (only) magical powers of non-physical souls but to involve more mundane psychological capacities - those that allow us to control our own behavior, change our habits, overcome addictions, exercise willpower, and consciously consider the sort of life we want to lead. If people regard free will as including these sorts of capacities, then telling them that they don't have free will could have detrimental effects on their self-conception, interpersonal relations, and moral behavior, as well as on our political debates and legal practices. It could make them more fatalistic, less likely to exert what powers of rational deliberation and willpower they do have, and less motivated to act morally (Baumeister et al. 2009). Hence it is crucial both that we understand people's conception of free will and that we examine critically what scientific discoveries actually tell us about free will. ${ }^{1}$ 
See also: VOLITION AND THE WILL (13); REASONS AND CAUSES (17); ACTION EXPLANATION AND THE UNCONSCIOUS (22); MENTAL CAUSATION AND EPIPHENOMENALISM (23); THE EXPLANATORY ROLE OF CONSCIOUSNESS (24); FREE WILL AND DETERMINISM (38); RESPONSIBILITY AND AUTONOMY (39); INTENTIONAL ACTION IN FOLK PSYCHOLOGY (45).

\section{Note}

1 I am grateful for helpful comments from Al Mele, Manuel Vargas, Andrea Scarantino, George Graham, and the audience at the 2009 meeting of the APA Central. This chapter was completed in part with support from a grant from the University of Chicago Arete Initiative and the John Templeton Foundation.

\section{References}

Baer, J., Kaufmann, J., and Baumeister, R. (eds) (2008). Are We free? Psychology and Free Will. New York: Oxford University Press.

Bargh, J. (2008). Free will is un-natural. In Baer, Kaufmann, and Baumeister (eds), 128-154.

Bargh, J. and Ferguson, M. (2000). Beyond behaviorism: On the automaticity of higher mental processes. Psychological Bulletin, 126, 925-945.

Baumeister, R. (2008). Free will, consciousness, and cultural animals. In Baer, Kaufmann, and Baumeister (eds), 65-85.

Baumeister, R., Masicampio, E., and DeWall, C. (2009). Prosocial benefits of feeling free: Disbelief in free will increases aggression and reduces helpfulness. Personality and Social Psychology Bulletin, 35, 260-268.

Craver, C. (2007). Explaining the Brain: Mechanisms and the Mosaic Unity of Neuroscience. New York: Oxford University Press.

Dennett, D. (1991). Consciousness Explained. New York: Back Bay Books.

Doris, J. (2002). Lack of Character: Personality and Moral Behavior. New York: Cambridge University Press.

Gollwitzer, P. M. (1999). Implementation intentions. American Psychologist, 54, 493-503.

Greene, J., and Cohen, J. (2004). For the law, neuroscience changes nothing and everything. Philosophical Transactions of the Royal Society of London B, 359, 1775-1778.

Greene, J. (2007). The secret joke of Kant's soul. In W. Sinnott-Armstrong (ed.), Moral Psychology, Vol. 3: The Neuroscience of Morality: Emotion, Disease, and Development. Cambridge, MA: MIT Press, 35-79.

Haidt, J. (2001). The emotional dog and its rational tail: A social intuitionist approach to moral judgment. Psychological Review, 108, 814-834.

Libet, B. (1985). Unconscious cerebral initiative and the role of conscious will in voluntary action. Behavioral and Brain Sciences, 8, 529-566.

Libet, B. (1999). Do we have free will? In B. Libet, A. Freeman, and K. Sutherland (eds), The Volitional Brain. Exeter: Imprint Academic, 47-57.

Kane, R. (1996). The Significance of Free Will. New York: Oxford University Press.

Kim, J. (1998). Mind in a Physical World. Cambridge, MA: MIT Press.

McKenna, M. (2004). Compatibilism. In E. Zalta (ed.), The Stanford Encyclopedia of Philosophy URL: http://plato.stanford.edu/entries/compatibilism.

Mele, A. (2009). Effective Intentions: The Power of Conscious Will. New York: Oxford University Press. 


\section{EDDY NAHMIAS}

Montague, R. (2008). Free will. Current Biology, 18, R584-R585.

Nahmias, E. (2002). When consciousness matters: A critical review of Daniel Wegner's The Illusion of Conscious Will. Philosophical Psychology, 15, 527-541.

Nahmias, E. (2007a). Autonomous agency and social psychology. In M. Marraffa, M. Caro, and F. Ferretti (eds), Cartographies of the Mind: Philosophy and Psychology in Intersection. Dordrecht: Springer, 169-185.

Nahmias, E., Coates, J., and Kvaran, T. (2007b). Free will, moral responsibility, and mechanism: Experiments on folk intuitions. Midwest Studies in Philosophy, 31, 214-232.

Nahmias, E., Morris, S., Nadelhoffer, T., and Turner, J. (2006). Is incompatibilism intuitive? Philosophy and Phenomenological Research, 73, 28-53.

Ross, L. and Nisbett, R. (1991). The Person and the Situation: Perspectives of Social Psychology. New York: McGraw-Hill.

Soon, C., Brass, M., Heinze, H., and Haynes, J. (2008). Unconscious determinants of free decisions in the human brain. Nature Neuroscience, 11, 543-545.

Tancredi, L. (2007). The neuroscience of 'free will.' Behavioral Sciences and the Law, 25, 295-308.

Van Inwagen, P. (1983). An Essay on Free Will. Oxford: Oxford University Press.

Wegner, D. (2002). The Illusion of Conscious Will. Cambridge, MA: MIT Press.

Wegner, D. (2008). Self is magic. In Baer, Kaufmann, and Baumeister (eds), 226-247.

Youngsteadt, E. (2008). Case closed for free will? Science NOW Daily News, 4/14/2008. 